\title{
Predicting postoperative pancreatic fistula in pancreatic head resections: which score fits all?
}

\author{
Mariam Adamu ${ }^{1} \cdot$ Verena Plodeck $^{2} \cdot$ Claudia Adam $^{1} \cdot$ Anne Roehnert $^{2} \cdot$ Thilo Welsch $^{1} \cdot$ Juergen Weitz $^{1}$. \\ Marius Distler ${ }^{1}$ (1)
}

Received: 5 November 2020 / Accepted: 23 July 2021 / Published online: 9 August 2021

(c) The Author(s) 2021

\begin{abstract}
Purpose Postoperative pancreatic fistula (POPF) is a major complication of pancreatic surgery and can be fatal. Better stratification of patients into risk groups may help to select those who might benefit from strategies to prevent complications. The aim of this study was to validate ten prognostic scores in patients who underwent pancreatic head surgery.

Methods A total of 364 patients were included in this study between September 2012 and August 2017. Ten risk scores were applied to this cohort. Univariate and multivariate analyses were performed considering all risk factors in the scores. Furthermore, the stratification of patients into risk categories was statistically tested.

Results Nine of the scores (Ansorge et al., Braga et al., Callery et al., Graham et al., Kantor et al., Mungroop et al., Roberts et al., Yamamoto et al. and Wellner et al.) showed strong prognostic stratification for developing POPF ( $p<0.001)$. There was no significant prognostic value for the Fujiwara et al. risk score. Histology, pancreatic duct diameter, intraabdominal fat thickness in computed tomography findings, body mass index, and C-reactive protein were independent prognostic factors on multivariate analysis.

Conclusion Most risk scores tend to stratify patients correctly according to risk for POPF. Nevertheless, except for the fistula risk score (Callery et al.) and its alternative version (Mungroop et al.), many of the published risk scores are obscure even for the dedicated pancreatic surgeon in terms of their clinical practicability. There is a need for future studies to provide strategies for preventing POPF and managing patients with high-risk stigmata.
\end{abstract}

Keywords Postoperative pancreatic fistula $\cdot$ Complications after pancreatic head resection $\cdot$ Risk score $\cdot$ External validation $\cdot$ Pancreatic surgery

\section{Introduction}

Postoperative pancreatic fistula (POPF) [1] is a major complication of pancreatic surgery. The main cause of POPF is insufficiency of the pancreatic anastomosis [2]. Although pain and sepsis are the main morbidity elements of POPF, mortality can occur due to serious adverse events like postpancreatectomy hemorrhage (PPH) [3]. Life-threatening PPH from the gastroduodenal or splenic artery stump, in

Marius Distler

marius.distler@uniklinikum-dresden.de

1 Department of Visceral, Thoracic and Vascular Surgery, University Hospital Carl Gustav Carus, Technical University Dresden, Fetscherstraße 74, 01307 Dresden, Germany

2 Department of Radiology, University Hospital Carl Gustav Carus, Technical University Dresden, Dresden, Germany the case of pancreatic head or tail resection respectively, has been documented [4,5]. Advances in chemotherapy in the last decade have led to an enormous increase in the rate of pancreatic resections, mainly due to an increase in the proportion of patients with borderline resectable pancreatic ductal adenocarcinoma (PDAC) [6, 7].

The incidence of POPF has been shown to reach up to more than $30 \%$ [4, 5, 8-10] in a number of studies, even in high-volume pancreas centers. However, the management of patients in these high-volume centers plays a key role in the associated reduced mortality. Pancreatic fistulas are classified as biochemical leak, and grades B and C POPF according to the International Study Group of Pancreatic Surgery [11]. Grades B and C are considered clinically relevant POPFs, in which a change of management or reoperation is necessary and multiorgan failure or even death can occur. Benign tumors of the pancreas and chronic uncomplicated 
pancreatitis have an excellent prognosis. Thus, it is unacceptable to have an increased risk of mortality associated with postoperative complications due to POPF. Significant efforts have to be made to adequately predict a patient's risk for developing POPF and ultimately identify patients who would benefit from additional approaches and closer perioperative monitoring. To improve the prognostic power of individual clinicopathological variables, several prognostic scoring systems have been proposed which combine multiple factors. To date, however, there is very limited data on the generalizability of these scoring systems.

Selection and stratification of patients into groups according to POPF risk are important for the application of additional surgical and clinical strategies in patient management. The aim of the present study was to select, validate and perform a head-to-head comparison of ten different prognostic (POPF) scoring systems in an independent cohort of patients with pancreatic head resection and prove their clinical practicability.

\section{Materials and methods}

\section{Study population and data collection}

This cohort study was carried out at the Department of Visceral, Thoracic and Vascular Surgery, University Hospital Carl Gustav Carus, Technical University Dresden. Patients who underwent either laparoscopic or conventional pyloruspreserving pancreaticoduodenectomy (PPPD), duodenumpreserving pancreatic head resection (DPPHR), or the Whipple procedure for chronic pancreatitis or benign or malignant lesions from September 2012 to August 2017 were prospectively enrolled in the study and their data included in a database. Patients with recurrent pancreatic surgery were excluded from the study. Follow-up examinations limited to this study were carried out at regular intervals and ended at month 3 after surgery. There was no loss to follow-up at 90 days after surgery.

At baseline, all participants completed a standard comprehensive questionnaire providing information on sociodemographic characteristics, medical history, current health status, and lifestyle factors. Data on diagnostic workup and tumor markers in the case of malignancy were collected from the hospital's electronic database, patient files, and external reports. Information on patient follow-up was collected from the hospital's electronic database. A visit to the special pancreatic consultation hour in our outpatient clinic takes place 3 months post-surgery at the latest. Patient follow-up took place until 90 days after surgery. This study was approved by the ethics committee of the Technical University Dresden (BO-EK-62022020) and performed according to the Declaration of Helsinki.

\section{Evaluation of prognostic scoring systems}

Ansorge et al. [12] based their study on a cohort of 110 prospectively observed patients. The two prognostic factors included were pancreatic consistency (PC) and pancreatic duct diameter (PDD). Patients were assigned points according to these prognostic factors and stratified into 3 groups ("no risk," "one risk factor," and "two risk factors"). Braga et al. [13] performed a study on 700 patients, developed a score based on 469 of the patients, and validated it on 231. Predictors included in the scoring system were PC, PDD, operative blood loss, and American Society of Anesthesiologists (ASA) score. Patients were assigned points based on these risk factors and stratified into four groups according to their points. Similarly, Callery et al. [14] created a score based on PC, PDD, histology, and blood loss. The score was derived from 233 patients and validated prospectively on 212 patients. Outcomes were evaluated across 4 risk groups ("negligible risk," 0 points; "low risk," 1-2 points; "intermediate risk," 3-6 points; "high risk," 7-10 points). In a study from Japan, Fujiwara et al. [15] used different cutoff levels of albumin and C-reactive protein (CRP) to create a postoperative inflammatory score (PIS) which stratified patients into 3 groups ("PIS 0," "PIS 1," and "PIS 2"). Graham et al. [16] used age, body mass index (BMI), amylase level in drain on postoperative day two (POD 2) and PDD to estimate the probability of developing POPF. Kantor et al. [17] selected significant variables from a univariate analysis and included them in a multivariate analysis to create a model based on gender, BMI, preoperative total bilirubin, PDD, and gland texture. A 10-point model was created based on these variables. This model stratified patients into 4 groups ("negligible risk," "low risk," "intermediate risk," and "high risk"). Mungroop et al. [18] created a final model of three strong predictors of POPF (soft pancreatic texture, decreasing PDD, and increasing BMI) based on the full model by Callery et al. [14] to predict the probability of POPF. In total, 2850 patients from 21 institutions from 4 countries were used for designing the model and its external validation. Roberts et al. [19] based their study on 325 patients. Using BMI and PDD, a risk score was derived from a model, which predicted the likelihood of developing POPF. In addition, a receiver operating characteristic (ROC) curve was produced and used to test the accuracy of the score. Wellner et al. [20] used preoperative variables, which included age, histology, history of smoking, weight loss, and pancreatitis, to stratify patients into "high-," "medium-," and "low-risk" groups. Yamamoto et al. [21] internally validated a score based on significant variables on univariate and multivariate analysis. The scoring system included main pancreatic duct 
(MPD), computed tomography findings on the relation of the portal vein (involved or away), gender, intraabdominal fat thickness [distance from the internal face of the rectus abdominis (linea alba) to the rear wall of the aorta at the level of the umbilicus], and histology of either pancreatic cancer or other diseases. Patients were assigned " 0 ," " 1 " or " 2 " points depending on the variables and the likelihood of developing POPF was estimated. An overview of the studies is presented in Table 1.

\section{Statistical analyses}

A stepwise strategy was used to validate the selected risk scores. First, univariate analysis was performed including all variables in the selected scores. In order to reduce the standard error, Firth's bias-reduced logistic regression was used for the univariate analysis. For the multivariate analysis, all significant univariate variables were considered and a stepwise backward selection procedure with penalized likelihood ratio test was used to select variables. The significance level for inclusion in the model was set at 0.05 . The c-statistic was estimated in order to assess the predictive capacity of single models. The performance of the multivariate model was estimated by comparing the Akaike information criterion (AIC) of single factors included in the model and their combinations. In the descriptive analysis, continuous variables were expressed as median and interquartile range. Categorical variables were presented as number and percentage per group. The variables in the scores, on the other hand, were categorized as presented in the selected publications. For a better overview of the incidence of POPF, bar graphs were created where stratification into risk groups was available. Only patients with complete data on all variables were included in the respective statistical models. Statistical analyses were performed using the R 3.5.3 software [22].

\section{Results}

\section{Patient characteristics}

This cohort study included a total of 358 patients who underwent pancreatic head resection in the form of either the Whipple procedure, DPPHR, or PPPD (Table 2). The study comprised 145 (41\%) women and 213 (59\%) men. The median age of all patients was 66 years (interquartile range 56-74 years). Ninety-six percent of all patients underwent conventional surgery, $2 \%$ had minimally invasive surgery, and in another $2 \%$ conversion from minimally invasive to open surgery was required. The majority of patients $(n=245$, $68 \%$ ) underwent PPPD. More than 70\% of the surgeries performed were due to malignancy. Clinically relevant POPF was diagnosed in 104 (29\%) patients.

\section{Validation of prognostic scoring systems}

We used a two-stage approach for external validation of the proposed scoring systems by performing uni- and multivariate analyses of the single variables included in the selected scores, followed by application of the calculated scores to patients operated at our clinic. In the ten prognostic scoring systems evaluated, 17 different clinicopathological variables were analyzed. On univariate analysis, stratification was performed according to the cutoff levels of individual scores (Table 3). A negative strength of association was seen for history of weight loss (OR 0.51, CI 0.32-0.82), history of pancreatitis (OR 0.43, CI 0.24-0.73), low postoperative CRP (OR 0.50, CI 0.29-0.85), and increase in PDD (OR 0.58, CI $0.49-0.68)$. A very high positive strength of association with the risk of developing POPF was seen in patients with a soft pancreatic consistency (OR 13.65, CI 6.65-30.83). Patients with a PDD $<3 \mathrm{~mm}$ had very high odds (OR 12.89,

Table. 1 Overview of publications on the prognostic scores for postoperative pancreatic fistula

\begin{tabular}{llllll}
\hline Author & Country & Published & Recruited & $N$ & Stratification \\
\hline Ansorge et al & Sweden & 2012 & $2008-2010$ & 110 & no risk, one risk factor, two risk factors \\
Braga et al & Italy & 2011 & $2002-2010$ & $700^{\mathrm{b}}$ & $0-3,4-7,8-11,12-15$ \\
Callery et al & USA & 2013 & $2002-2011$ & $445^{\mathrm{b}}$ & negligible risk, low risk, intermediate risk, high risk \\
Fujiwara et al & Japan & 2013 & $2001-2011$ & $297^{\mathrm{b}}$ & PIS 0, PIS 1, PIS 2 \\
Graham et al & USA & 2013 & $2007-2012$ & 146 & probability estimate \\
Kantor et al & USA & 2017 & $2011-2014$ & $4827^{\mathrm{b}}$ & negligible risk, low risk, intermediate risk, high risk \\
Mungroop et al & Multiple & 2019 & $2007-2016$ & $2850^{\mathrm{b}}$ & low risk, intermediate risk, high risk \\
Roberts et al & England & 2014 & $2007-2012$ & $325^{\mathrm{b}}$ & probability estimate \\
Wellner et al & Germany & 2010 & $2006-2010$ & $341^{\mathrm{b}}$ & low risk, medium risk, high risk \\
Yamamoto et al & Japan & 2011 & $2004-2009$ & $387^{\mathrm{b}}$ & $0,1,2$ \\
\hline
\end{tabular}

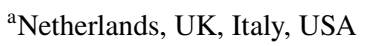

${ }^{\mathrm{b}}$ Includes validation population 
Table. 2 Overview of study population

\begin{tabular}{llll}
\hline & $n$ & nav & $\%$ \\
\hline Gender & & & \\
Female & 145 & 358 & 41 \\
Male & 213 & 358 & 59 \\
Age (years) & & & \\
Median (IQR) & $66^{\mathrm{a}}$ & $56^{\mathrm{b}}$ & $74^{\mathrm{b}}$ \\
Surgery mode & & & \\
Conventional & 345 & 358 & 96 \\
Laparoscopic & 7 & 358 & 2 \\
Converted & 6 & 358 & 2 \\
Surgery type & & & \\
PPPD & 245 & 358 & 68 \\
Whipple operation & 62 & 358 & 17 \\
DPPHR & 51 & 358 & 14 \\
Histology & & & \\
Benign & 103 & 358 & 29 \\
Malignant & 255 & 358 & 71 \\
POPF grade & & 358 & \\
None & 239 & 358 & 67 \\
Biochemical leak & 15 & 358 & 15 \\
B & 54 & & \\
C & 50 & & \\
\hline
\end{tabular}

$D P P H R$, duodenum-preserving pancreatic head resection; $I Q R$, interquartile range; $n$, number; nav, number available; $P O P F$, postoperative pancreatic fistula; $P P P D$, pylorus-preserving pancreaticoduodenectomy

${ }^{\text {a Median }}$

${ }^{\mathrm{b}} \mathrm{IQR}$

CI 6.60-26.92) of developing POPF. A medium positive strength of association was seen in patients with a histology other than PDAC or pancreatitis (OR 5.75, CI 3.53-9.53), and an MPD index <0.25 (OR 5.50, CI 3.31-9.37). Lower ORs for developing POPF were estimated for distance of tumor from portal vein (OR 3.64, CI 1.32-13.77), a BMI $\geq$ 25 (OR 3.06, CI 1.91-4.94), histology other than PDAC (OR 2.86, CI 1.75-4.78), intraabdominal fat thickness $>6.5 \mathrm{~cm}$ (OR 2.66, CI 1.33-5.87), and amylase in drain (OR 1.06, CI 1.04-1.09).

On multivariate analysis, histology other than PDAC or pancreatitis (OR 3.98, CI 2.17-7.44), intraabdominal fat thickness $>6.5 \mathrm{~cm}$ (OR 2.67, CI 1.01-7.13), PDD according to the Callery et al. stratification (OR reaching 11.30 for PDD > 1-2 mm), and higher BMI (OR 1.08, CI 1.01-1.16) were strongly associated with POPF. Low postoperative CRP (OR 1.06, CI 1.04-1.09) had a negative strength of association with incidence of POPF (Table 4).

A two-step approach was used to estimate the performance of the multivariate model. First, the AIC values of single factors in a score were estimated and compared to those of the respective scores. In a number of scores, the
AIC values of single factors were lower than that of the respective score model, meaning that the scores were unnecessarily complex for predicting POPF (data not shown). Furthermore, the AIC values of all single factors of the multivariate model were estimated and compared to that of the multivariate model (Table 5). As illustrated, it can be concluded that in some scores, single factors might be sufficient to predict POPF, because they have a better model fit than the score itself. However, our multivariate model has the perfect fit for this cohort and therefore, the lowest AIC of 259 compared to all single variables.

Figure 1(A-J) shows an overview of the ten risk scores according to the different definitions. An adequate risk stratification was seen when the scores of Ansorge et al., Braga et al., Callery et al., Graham et al., Kantor et al., Mungroop et al., Roberts et al., Yamamoto et al., and Wellner et al. were applied to our cohort $(p<0.001)$. There was no significant prognostic value for the Fujiwara et al. risk score $(p=0.195)$. The predictive capacity of the Callery et al. and Mungroop et al. models for developing POPF was estimated as shown in Fig. 2(A-B). An overview of the model performance of each score is shown in Table 6.

\section{Discussion}

To the authors' knowledge, this is the first study to perform a head-to-head comparison and externally validate ten different published risk scores for POPF in an independent cohort of patients who underwent pancreatic head resection. On univariate analyses, several clinicopathological variables such as BMI, PDD, gland texture, histology, history of pancreatitis, MPD index, involvement of portal vein, intraabdominal thickness, and amylase in drain showed a strong association with POPF. A negative association with POPF was seen for history of pancreatitis, low postoperative CRP, and weight loss. No significant association with POPF could be found for multiple variables including gender, preoperative bilirubin, age at surgery, history of smoking, blood loss, albumin, and ASA classification. In line with these findings, application of the evaluated clinical risk scores to our patient population revealed a strong and clinically relevant stratification of patients' risk for POPF by the scores of Ansorge et al., Braga et al., Callery et al., Graham et al., Kantor et al., Mungroop et al., Roberts et al., Yamamoto et al., and Wellner et al. There was no significant value for the Fujiwara et al. risk score.

As illustrated by most of the scores validated in this article, correct stratification of each patient according to risk factors is necessary in order to accurately predict the risk of POPF. Although the stratification of variables in the different scores differed, the tendency to predict risk of POPF was consistent across the different scores for the same variables 
Table. 3 Univariate analysis including all variables as presented in the scores and their association with POPF

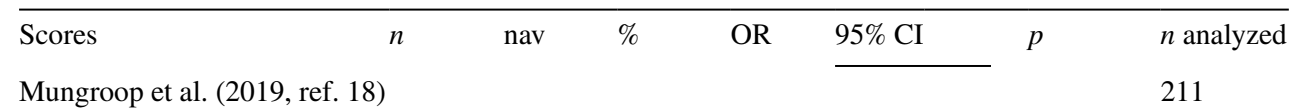

PDD (truncated at $5 \mathrm{~mm}$ )

\begin{tabular}{llllllll}
\hline Median (IQR) & $4^{\mathrm{d}}$ & $2^{\mathrm{e}}$ & $5^{\mathrm{e}}$ & 0.46 & 0.37 & 0.56 & $<0.001$ \\
\hline Gland texture & & & & & & & \\
$\quad$ Firm & 113 & 228 & 50 & & & & \\
Soft & 115 & 228 & 50 & 13.65 & 6.65 & 30.83 & $<0.001$ \\
BMI & & 364 & 100 & & & & \\
Median (IQR) & $24.61^{\mathrm{d}}$ & $22.13^{\mathrm{e}}$ & $27.72^{\mathrm{e}}$ & 1.16 & 1.10 & 1.23 & $<0.001$
\end{tabular}

Kantor et al. (2017, ref. 17)

Gender

$\begin{array}{lccccccc}\text { Female } & 147 & 364 & 40 & & & & \\ \quad \text { Male } & 217 & 364 & 60 & 1.59 & 0.99 & 2.58 & 0.05 \\ \text { BMI } & & & & & & & \\ <25 & 200 & 364 & 55 & & & & \\ \geq 25 & 164 & 364 & 45 & 3.06 & 1.91 & 4.94 & <0.001 \\ \text { Bilirubin } & \\ \geq 2 \mathrm{mg} / \mathrm{dl} & 85 & 364 & 23 & & & & \\ <2 \mathrm{mg} / \mathrm{dl} & 279 & 364 & 77 & 1.65 & 0.94 & 3.00 & 0.08 \\ \text { PDD } & & & & & & & \\ \geq 6 \mathrm{~mm} & 105 & 343 & 31 & & & & \\ 3-<6 \mathrm{~mm} & 133 & 343 & 39 & 3.88 & 1.87 & 8.81 & <0.001 \\ <3 \mathrm{~mm} & 105 & 343 & 31 & 11.50 & 5.54 & 26.21 & <0.001 \\ \text { Gland consistency } & & & & & & & \\ \text { Firm/intermediate } & 113 & 228 & 50 & & & & \\ \text { Soft } & 115 & 228 & 50 & 13.65 & 6.65 & 30.83 & <0.001\end{array}$

Roberts et al. (2014, ref. 19)

BMI

Median (IQR)

PDD (mm)

median (IQR)

Ansorge et al. (2012, ref. 12)

Pancreatic consistency

$1 / 2$

$3 / 4$

$\operatorname{PDD}(\mathrm{mm})$

$>4$

$3-4$

$<3$

$<2$

Callery et al. (2013, ref. 14)

$\begin{array}{lllllll}24.61^{\mathrm{d}} & 22.13^{\mathrm{e}} & 27.72^{\mathrm{e}} & 1.16 & 1.10 & 1.23 & <0.001 \\ 4^{\mathrm{d}} & 2^{\mathrm{e}} & 6^{\mathrm{e}} & 0.58 & 0.49 & 0.68 & <0.001\end{array}$

$\begin{array}{lllllll}4^{\mathrm{d}} & 2^{\mathrm{e}} & 6^{\mathrm{e}} & 0.58 & 0.49 & 0.68 & <0.001\end{array}$

Gland texture

\begin{tabular}{llllllll} 
Firm & 113 & 228 & 50 & & & \\
Soft & 115 & 228 & 50 & 13.65 & 6.65 & 30.83 & $<0.001$ \\
$\begin{array}{l}\text { Histology } \\
\text { PDAC/pancreatitis }\end{array}$ & 209 & 280 & 75 & & & & \\
$\begin{array}{l}\text { Other } \\
\text { PDD (mm) }\end{array}$ & 71 & 280 & 25 & 5.01 & 2.70 & 9.38 & $<0.001$ \\
$\geq 5$ & 151 & 343 & 44 & & & & \\
4 & 39 & 343 & 11 & 4.77 & 1.92 & 11.87 & $<0.001$ \\
3 & 48 & 343 & 14 & 9.34 & 4.24 & 21.50 & $<0.001$ \\
\hline
\end{tabular}

211

$113 \quad 228 \quad 50$

$115 \quad 228 \quad 50$

$\begin{array}{llll} & 13.65 & 6.65 & 30.83<0.001\end{array}$

$151 \quad 343 \quad 44$

$87 \quad 343 \quad 25$

$102 \quad 343 \quad 30$

$\begin{array}{llll}7.02 & 3.48 & 14.95<0.001\end{array}$

$\begin{array}{llll}12.89 & 6.60 & 26.92<0.001\end{array}$

$\begin{array}{llll}6.60 & 0.57 & 53.74 & 0.11\end{array}$

137 
Table. 3 (continued)

\begin{tabular}{|c|c|c|c|c|c|c|c|c|}
\hline \multirow{2}{*}{$\begin{array}{l}\text { Scores } \\
\text { Mungroop et al. (2019, ref. } 18\end{array}$} & \multirow{2}{*}{$n$} & \multirow[t]{2}{*}{ nav } & \multirow[t]{2}{*}{$\%$} & \multirow[t]{2}{*}{ OR } & \multicolumn{2}{|c|}{$95 \% \mathrm{CI}$} & \multirow[t]{2}{*}{$p$} & \multirow{2}{*}{$\begin{array}{l}n \text { analyzed } \\
211\end{array}$} \\
\hline & & & & & & & & \\
\hline \multicolumn{9}{|l|}{ PDD (truncated at $5 \mathrm{~mm}$ ) } \\
\hline Median (IQR) & $4^{\mathrm{d}}$ & $2^{\mathrm{e}}$ & $5^{\mathrm{e}}$ & 0.46 & 0.37 & 0.56 & $<0.001$ & \\
\hline 2 & 102 & 343 & 30 & 12.89 & 6.60 & 26.92 & $<0.001$ & \\
\hline$\leq 1$ & 3 & 343 & 1 & 6.60 & 0.57 & 53.74 & 0.11 & \\
\hline \multicolumn{9}{|l|}{ Blood loss (ml) } \\
\hline$\leq 400$ & 97 & 311 & 31 & & & & & \\
\hline $401-700$ & 103 & 311 & 33 & 0.75 & 0.39 & 1.41 & 0.37 & \\
\hline $701-1000$ & 56 & 311 & 18 & 1.46 & 0.72 & 2.94 & 0.29 & \\
\hline$>1000$ & 55 & 311 & 18 & 1.36 & 0.66 & 2.77 & 0.41 & \\
\hline Fujiwara et al. (2013, ref. 15) & & & & & & & & 310 \\
\hline \multicolumn{9}{|l|}{ Albumin $^{c}$} \\
\hline High & 187 & 321 & 58 & & & & & \\
\hline Low & 134 & 321 & 42 & 0.77 & 0.47 & 1.26 & 0.30 & \\
\hline \multicolumn{9}{|l|}{$\mathrm{CRP}^{\mathrm{c}}$} \\
\hline High & 76 & 350 & 22 & & & & & \\
\hline Low & 274 & 350 & 78 & 0.50 & 0.29 & 0.85 & 0.01 & \\
\hline Graham et al. (2013, ref. 16) & & & & & & & & 231 \\
\hline BMI & & 364 & 100 & & & & & \\
\hline Median (IQR) & $24.61^{\mathrm{d}}$ & $22.13^{\mathrm{e}}$ & $27.72^{\mathrm{e}}$ & 1.16 & 1.10 & 1.23 & $<0.001$ & \\
\hline Age & & 364 & 100 & & & & & \\
\hline Median (IQR) & $66^{\mathrm{d}}$ & $56^{\mathrm{e}}$ & $74^{\mathrm{e}}$ & 1.01 & 0.99 & 1.03 & 0.23 & \\
\hline Amylase in drain (umol/s*l) & & 249 & 68 & & & & & \\
\hline Median (IQR) & $1.31^{\mathrm{d}}$ & $0.16^{\mathrm{e}}$ & $5.86^{\mathrm{e}}$ & 1.06 & 1.04 & 1.09 & $<0.001$ & \\
\hline \multicolumn{9}{|l|}{$\mathrm{PDD}(\mathrm{mm})$} \\
\hline$\geq 3$ & 238 & 343 & 69 & & & & & \\
\hline$<3$ & 105 & 343 & 31 & 4.77 & 2.89 & 7.93 & $<0.001$ & \\
\hline Braga et al. (2011, ref. 13) & & & & & & & & 181 \\
\hline \multicolumn{9}{|l|}{$\mathrm{PDD}(\mathrm{mm})$} \\
\hline$>3$ & 190 & 343 & 55 & & & & & \\
\hline$\leq 3$ & 153 & 343 & 45 & 7.24 & 4.29 & 12.59 & $<0.001$ & \\
\hline \multicolumn{9}{|l|}{ Blood loss (ml) } \\
\hline$<700$ & 181 & 311 & 58 & & & & & \\
\hline$\geq 700$ & 130 & 311 & 42 & 1.64 & 1.00 & 2.71 & 0.05 & \\
\hline \multicolumn{9}{|l|}{ ASA } \\
\hline I & 10 & 361 & 3 & & & & & \\
\hline II & 156 & 361 & 43 & 0.37 & 0.10 & 1.44 & 0.14 & \\
\hline III & 195 & 361 & 54 & 0.60 & 0.17 & 2.32 & 0.45 & \\
\hline Yamamoto et al. (2011, ref. 2 & & & & & & & & 326 \\
\hline \multicolumn{9}{|l|}{ MPD index } \\
\hline$\geq 0.25$ & 187 & 343 & 55 & & & & & \\
\hline$<0.25$ & 156 & 343 & 45 & 5.50 & 3.31 & 9.37 & $<0.001$ & \\
\hline \multicolumn{9}{|l|}{ Distance from portal vein } \\
\hline Involved & 30 & 349 & 9 & & & & & \\
\hline Away & 319 & 349 & 91 & 3.64 & 1.32 & 13.77 & 0.01 & \\
\hline \multicolumn{9}{|l|}{ Histology } \\
\hline Pancreatic cancer & 156 & 362 & 43 & & & & & \\
\hline Other & 206 & 362 & 57 & 2.86 & 1.75 & 4.78 & $<0.001$ & \\
\hline Intraabdominal fat thickness & mm) & & & & & & & \\
\hline$\leq 65$ & 61 & 346 & 18 & & & & & \\
\hline
\end{tabular}


Table. 3 (continued)

\begin{tabular}{|c|c|c|c|c|c|c|c|c|}
\hline \multirow{2}{*}{\multicolumn{2}{|c|}{$\begin{array}{l}\text { Scores } \\
\text { Mungroop et al. (2019, ref. 18) }\end{array}$}} & \multirow[t]{2}{*}{ nav } & \multirow[t]{2}{*}{$\%$} & \multirow[t]{2}{*}{ OR } & \multicolumn{2}{|c|}{$95 \% \mathrm{CI}$} & \multirow[t]{2}{*}{$p$} & \multirow{3}{*}{$\begin{array}{l}n \text { analyzed } \\
211\end{array}$} \\
\hline & & & & & & & & \\
\hline \multicolumn{8}{|l|}{ PDD (truncated at $5 \mathrm{~mm}$ ) } & \\
\hline Median (IQR) & $4^{\mathrm{d}}$ & $2^{\mathrm{e}}$ & $5^{\mathrm{e}}$ & 0.46 & 0.37 & 0.56 & $<0.001$ & \\
\hline$>65$ & 285 & 346 & 82 & 2.66 & 1.33 & 5.87 & $<0.001$ & \\
\hline \multicolumn{9}{|l|}{ Gender } \\
\hline Female & 147 & 346 & 40 & & & & & \\
\hline Male & 217 & 346 & 60 & 1.59 & 0.99 & 2.58 & 0.05 & \\
\hline Wellner et al. (2010, ref & & & & & & & & 342 \\
\hline$\leq 66$ years & 189 & 364 & 52 & & & & & \\
\hline$>66$ years & 175 & 364 & 48 & 1.29 & 0.82 & 2.04 & 0.27 & \\
\hline \multicolumn{9}{|l|}{ Histology } \\
\hline Carcinoma/pancreatitis & 220 & 362 & 61 & & & & & \\
\hline Other & 142 & 362 & 39 & 5.75 & 3.53 & 9.53 & $<0.001$ & \\
\hline \multicolumn{9}{|l|}{ History of smoking } \\
\hline No & 246 & 360 & 68 & & & & & \\
\hline Yes & 114 & 360 & 32 & 0.61 & 0.36 & 1.01 & 0.06 & \\
\hline \multicolumn{9}{|l|}{ Weight loss } \\
\hline No & 153 & 355 & 43 & & & & & \\
\hline Yes & 202 & 355 & 57 & 0.51 & 0.32 & 0.82 & $<0.001$ & \\
\hline \multicolumn{9}{|c|}{ History of acute pancreatitis } \\
\hline No & 254 & 363 & 70 & & & & & \\
\hline Yes & 109 & 363 & 30 & 0.43 & 0.24 & 0.73 & $<0.001$ & \\
\hline
\end{tabular}

$A S A$, American Society of Anesthesiologists; BMI, body mass index; $C I$, confidence interval; $C R P$, C-reactive protein; $I Q R$, interquartile range; $M P D$, main pancreatic duct; $n$, number; nav, number available; $O R$, odds ratio; $p, p$ value; $P D A C$, pancreatic ductal adenocarcinoma; $P D D$, pancreatic duct diameter; $P O P F$, postoperative pancreatic fistula; $r e f$., reference number

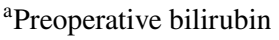

${ }^{\mathrm{b}}$ Ampullary, duodenal, cystic, islet cell

${ }^{c}$ Postoperative

${ }^{\mathrm{d}}$ Median

${ }^{\mathrm{e}} \mathrm{IQR} \%$, percentage

stratified differently. This is also graphically depicted in the figures, which show an increase in incidence of POPF as the score value increases. While the majority of the variables included in the scores are easy to obtain, some can only be acquired intra- or postoperatively. It is not always the case that PDD, gland texture, and histology type are determined preoperatively. On the other hand, blood loss can only be determined during or after surgery. CT findings and biopsy (when indicated) can help determine some of the abovementioned variables. Although CT findings are proximity measures, these measures are reproducible. The only subjective measure may be tumor infiltration of the portal vein. It is nevertheless challenging to stratify patients correctly preoperatively and discuss the risk of POPF in the outpatient setting. Therefore, application of most of the scores is limited in the preoperative setting. The ideal score to predict POPF would have to include variables that are obtainable pre- and intraoperatively, and also be reproducible in order to implement surgical or clinical strategies to avoid or reduce POPF-associated morbidity and mortality. It is therefore not surprising to find an association between a high concentration of amylase in drains and POPF. Risk stratification should begin preoperatively and can continue intraoperatively in order to allow for changes in surgical procedure such as drain placement, stenting of the pancreatic duct or proceeding to total pancreatectomy.

On univariate analysis, only four of the selected scores (Yamato et al. [21], Ansorge et al. [12], Mungroop et al. [18], Roberts et al. [19]) showed a significant association of all variables with POPF. Variables from these scores could be determined preoperatively by means of CT findings in addition to intraoperative data. However, the Callery et al. [14] fistula risk score is the most predominant. This score includes blood loss, which is difficult to adequately determine in time, when a change of surgical strategy might still be possible. The recently proposed alternative fistula risk 
Table. 4 Significant variables on multivariate analysis including 302 patients

\begin{tabular}{|c|c|c|c|c|c|}
\hline \multirow{2}{*}{$\begin{array}{l}\text { Score } \\
\text { Wellner et al }\end{array}$} & \multirow{2}{*}{$\begin{array}{l}\text { Variable } \\
\text { Histology of } \\
\text { other than } \\
\text { PDAC or pan- } \\
\text { creatitis }\end{array}$} & \multirow{2}{*}{$\begin{array}{l}\text { OR } \\
3.98\end{array}$} & \multicolumn{2}{|c|}{$95 \% \mathrm{CI}$} & \multirow{2}{*}{$\begin{array}{l}p \\
<0.001\end{array}$} \\
\hline & & & 2.17 & 7.44 & \\
\hline Yamamoto et al & $\begin{array}{l}\text { Intraabdomi- } \\
\text { nal thick- } \\
\text { ness }>65 \mathrm{~mm}\end{array}$ & 2.67 & 1.09 & 7.13 & 0.03 \\
\hline \multirow[t]{4}{*}{ Callery et al } & PDD 4 mm & 6.48 & 2.20 & 19.32 & $<0.001$ \\
\hline & PDD 3 mm & 7.98 & 3.22 & 20.78 & $<0.001$ \\
\hline & PDD 2 mm & 11.30 & 5.21 & 26.40 & $<0.001$ \\
\hline & $\mathrm{PDD} \leq 1 \mathrm{~mm}$ & 5.41 & 0.38 & 55.74 & 0.19 \\
\hline Fujiwara et al & $\mathrm{CRP}^{\mathrm{a}}$ & 0.44 & 0.21 & 0.88 & 0.02 \\
\hline Graham et al & BMI & 1.08 & 1.01 & 1.16 & 0.03 \\
\hline
\end{tabular}

$B M I$, body mass index; $C I$, confidence interval; $C R P, \mathrm{C}$-reactive protein; $O R$, odds ratio; $p, p$ value; $P D A C$, pancreatic ductal adenocarcinoma; $P D D$, pancreatic duct diameter

${ }^{\text {a}}$ Postoperative low

Table. 5 Akaike information criterion of single factors and the multivariate model

\begin{tabular}{lll}
\hline Score & Variable & AIC \\
\hline Wellner et al & $\begin{array}{c}\text { Histology of other than PDAC } \\
\text { or pancreatitis }\end{array}$ & 329 \\
Yamamoto et al & $\begin{array}{c}\text { Intraabdominal thick- } \\
\text { ness }>65 \mathrm{~mm}\end{array}$ & 369 \\
Callery et al & PDD $4 \mathrm{~mm}$ & 305 \\
Fujiwara et al & $\mathrm{CRP}^{\mathrm{a}}$ & 367 \\
Graham et al & BMI & 347 \\
Multivariate model probability & & 259 \\
\hline
\end{tabular}

$A I C$, Akaike information criterion; $B M I$, body mass index; $C R P$, C-reactive protein; $P D A C$, pancreatic ductal adenocarcinoma; $P D D$, pancreatic duct diameter

${ }^{\text {a }}$ Postoperative low

score by Mungroop et al. [18] ultimately provides adequate stratification of our cohort using variables which could be determined preoperatively. Although it was not the aim of this study to create a new risk score for POPF, the ideal score to predict POPF in our study population would have to include histology type, PDD, postoperative CRP, and BMI.

Total pancreatectomy may reduce perioperative morbidity and mortality by eliminating the risk of POPF. It should therefore be considered a suitable treatment option in patients with high-risk pancreatic anastomosis, especially in the age of autologous islet cell transplantation [23].

In the management of POPF [24], it is important to take into consideration reconstruction techniques. While some institutions favor pancreaticogastrostomy (PG), at our institution, pancreaticojejunostomy $(\mathrm{PJ})$ is routinely performed. However, there is still controversy about which technique is better for preventing POPF. A recent German multicenter randomized controlled trial demonstrated no significant difference in the rates of POPF in patients who underwent PG versus PJ [25]. In an Italian randomized study (The Verona Trial) [10] of patients at highest risk for developing POPF, patients who underwent either PG with externalized stent or PJ with externalized stent experienced similar rates of POPF of up to $50 \%$. However, it was concluded that patients who underwent PG had a higher risk of morbidity. Some meta-analyses [26-28] have shown a reduced incidence of insufficiency of the PG compared to PJ. PJ has been shown to be more physiological, as reduced incidence of impaired glucose tolerance, steatorrhea, and atrophic changes of the remaining pancreas have been reported in patients with PJ compared to patients with PG [29-31]. Nevertheless, it is hypothesized to adhere to well established surgical techniques to achieve best performance.

Placement of drains appears to play an important role in the diagnosis and treatment of relevant POPF [9]. Drains are used therapeutically to evacuate pancreatic secretion and prevent autodigestion, which can lead to death in the case of vessel erosion. On the other hand, therapeutic lavage could be performed using selected drains. This helps to control bacterial flora by preventing abscess formation and diluting the pancreatic enzymes, thereby reducing the risk of autodigestion. There are many studies available on the application and management of drains [32,33]. Using such measures in high-risk patients can reduce their risk of POPF complications.

There is some evidence that stent placement in the pancreatic duct for PJ drains trypsin distal to the anastomosis and supports healing of the latter, thereby reducing complications associated with POPF [34]. However, there are complications associated with both external and internal

Fig. 1 A-Bar graph demonstrating incidence of POPF according to Ansorge et al. risk stratification. POPF, postoperative pancreatic fistula. B-Bar graph demonstrating incidence of POPF according to Braga et al. risk stratification. POPF, postoperative pancreatic fistula. C-Bar graph demonstrating incidence of POPF according to Callery et al. risk stratification. POPF, postoperative pancreatic fistula. DBar graph demonstrating incidence of POPF according to Fujiwara et al. risk stratification. POPF, postoperative pancreatic fistula. $\mathbf{E}-$ Bar graph demonstrating incidence of POPF according to Graham et al. probability estimation. POPF, postoperative pancreatic fistula. F-Bar graph demonstrating incidence of POPF according to Kantor et al. risk stratification. POPF, postoperative pancreatic fistula. G-Bar graph demonstrating incidence of POPF according to Mungroop et al. probability estimation. POPF, postoperative pancreatic fistula. $\mathbf{H}-$ Bar graph demonstrating incidence of POPF according to Roberts et al. probability estimation. POPF, postoperative pancreatic fistula. I-Bar graph demonstrating incidence of POPF according to Wellner et al. risk stratification. POPF, postoperative pancreatic fistula. $\mathbf{J}-$ Bar graph demonstrating incidence of POPF according to Yamato et al. risk stratification. POPF, postoperative pancreatic fistula 

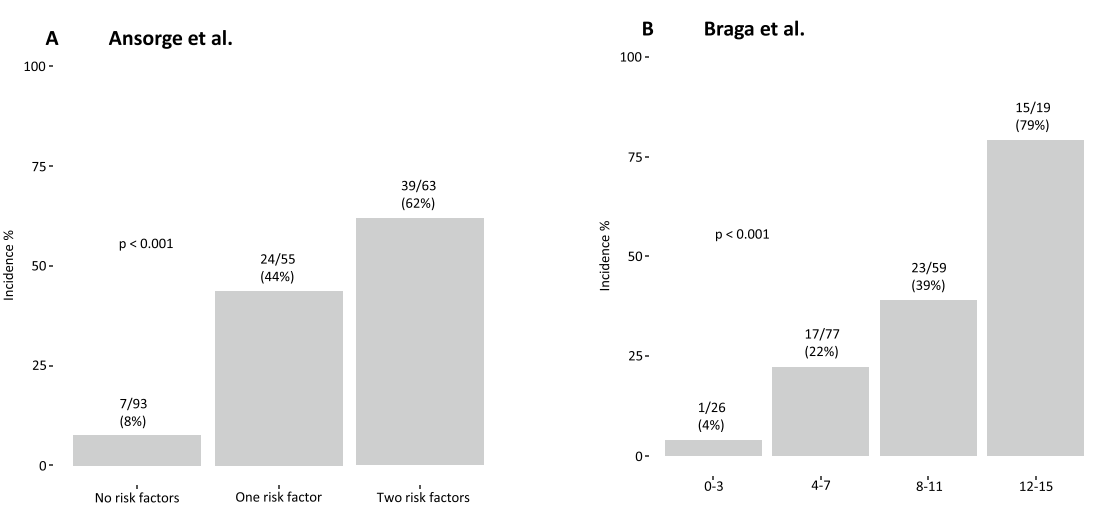

D Fujiwara et al.

100

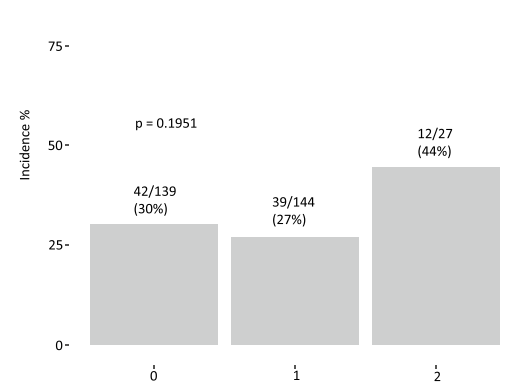

G Mungroop et al.

$$
100
$$

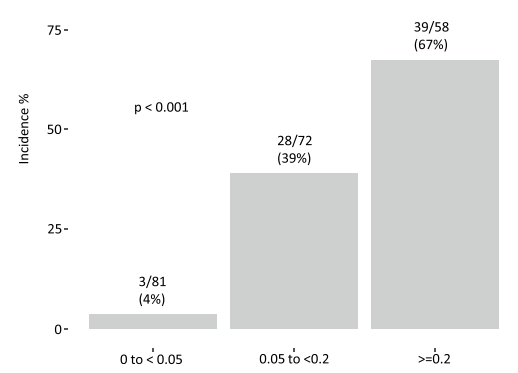

J Yamamoto et al.

100

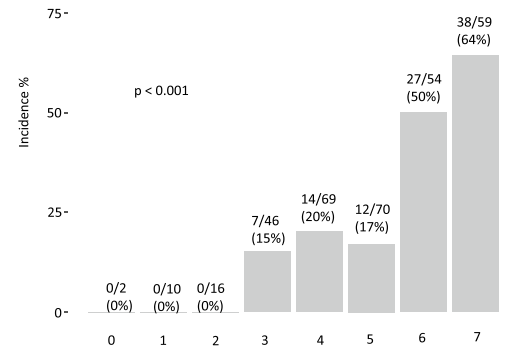

B Braga et al.

C Callery et al.

100 -

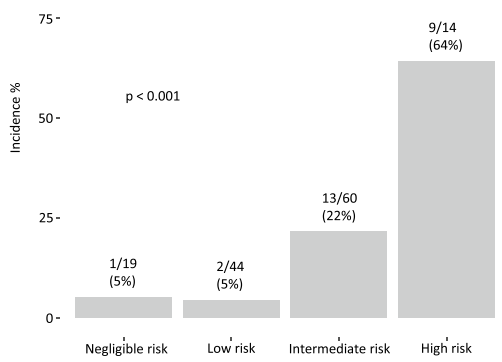

E Graham et al.

F Kantor et al.

100
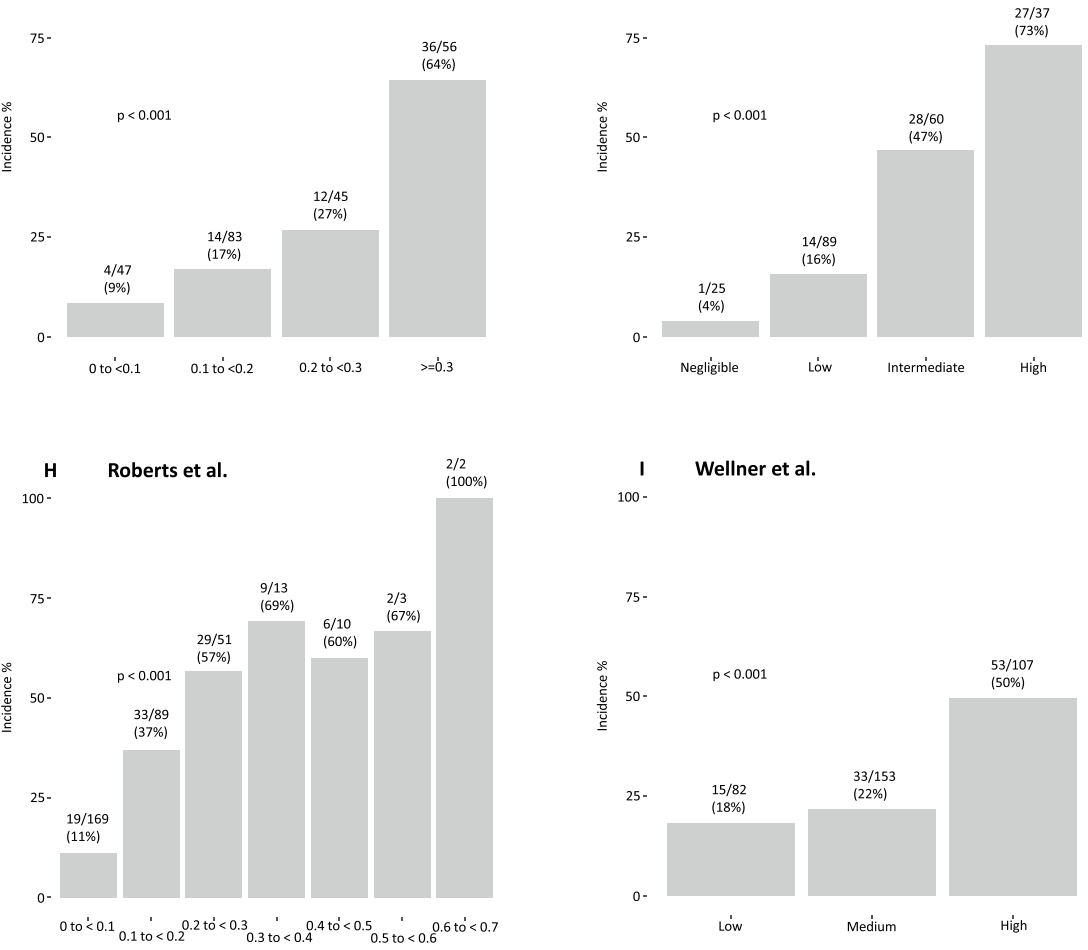

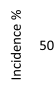

$53 / 107$
(50\%)

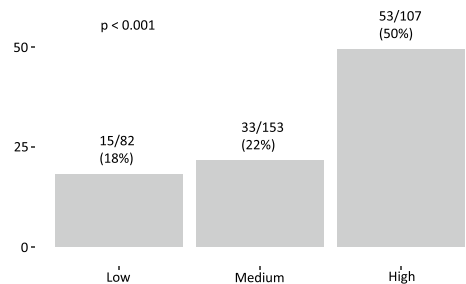

Low

I Wellner et al.

$75-$ 

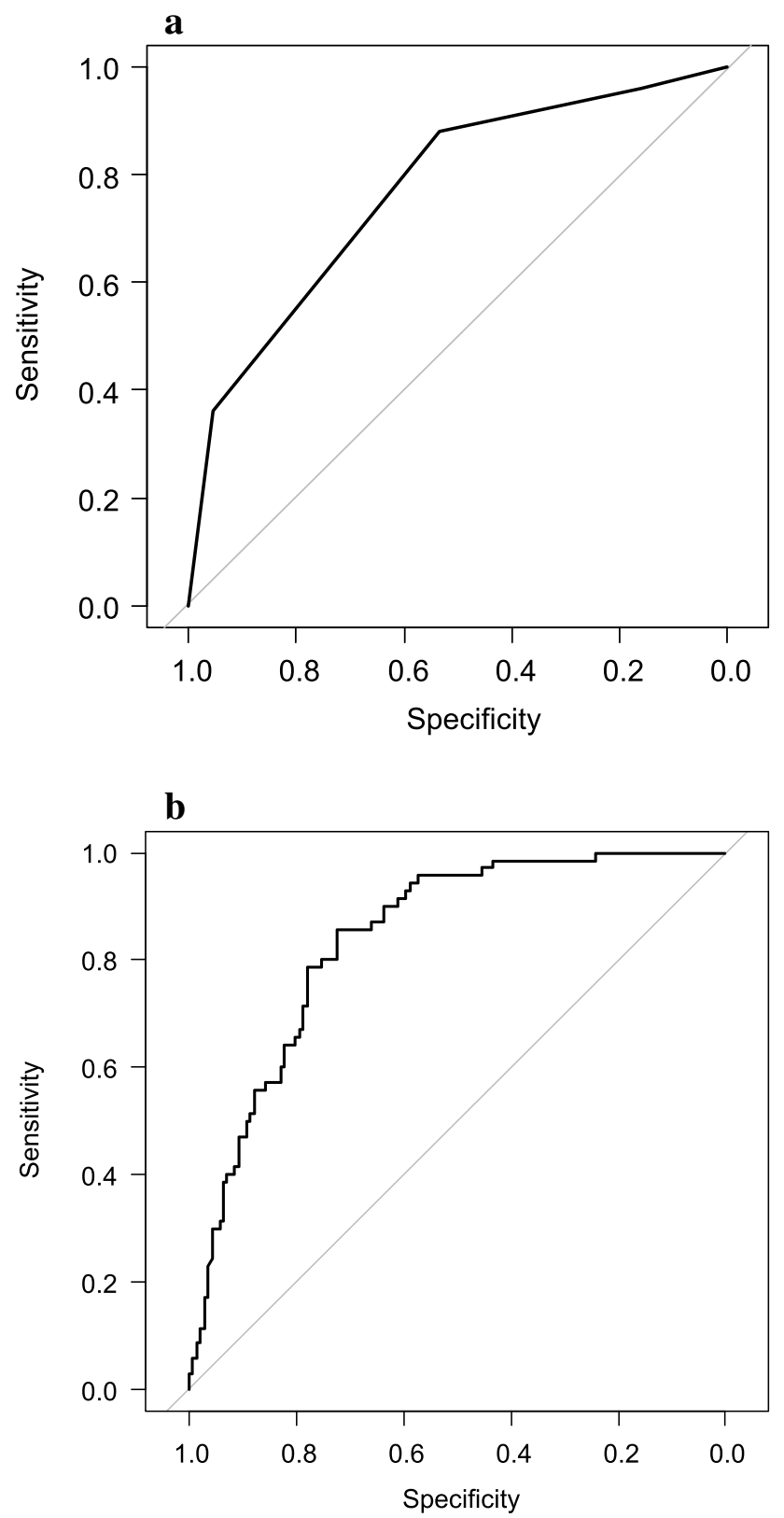

Fig. 2 A-ROC curve for POPF, comparison to Callery et al. C-statistic $($ AUC) $=0.80, p=0.00,($ CI 0.68-0.91). B-ROC curve for POPF, comparison to Mungroop et al. C-statistic $(\mathrm{AUC})=0.84$, $p=0.00$, (CI 0.79-0.89). AUC, area under the curve; POPF, postoperative pancreatic fistula; ROC, receiver operating characteristic

stent placement, including stent dislocation, excessive loss of digestive fluid, and ascending infection leading to cholangitis and subsequent liver abscess formation. Several RCTs have not shown a better performance in patients with stent placement for PJ compared to patients without stent with regard to incidence of POPF [34, 35]. However, it is still not clear whether stent implantation really helps to reduce morbidity associated with POPF.
Table. 6 Overview of the model performance of the selected scores

\begin{tabular}{llll}
\hline Score & AUC & CI & \\
\cline { 3 - 4 } Ansorge et al & 0.79 & 0.73 & 0.85 \\
\hline Braga et al & 0.74 & 0.67 & 0.81 \\
Callery et al & 0.80 & 0.68 & 0.91 \\
Fujiwara et al & 0.51 & 0.45 & 0.58 \\
Graham et al & 0.76 & 0.68 & 0.83 \\
Kantor et al & 0.82 & 0.76 & 0.88 \\
Mungroop et al & 0.84 & 0.79 & 0.89 \\
Roberts et al & 0.76 & 0.71 & 0.81 \\
Wellner et al & 0.68 & 0.62 & 0.75 \\
Yamamoto et al & 0.76 & 0.70 & 0.82 \\
\hline
\end{tabular}

$A U C$, area under the curve; $C I$, confidence interval

Topical application of fibrin glue to the pancreatic anastomosis was thought to reduce POPF by sealing torn pancreatic tissue [36]. Most reports tend to suggest that this procedure has no effect whatsoever on POPF [37-39]. Similarly, omental wrapping techniques have also been evaluated and were thought to prevent POPF and associated bleeding. Although a reduction in intraabdominal complications was seen, there was no reduction in POPF [40, 41]. Octreotide and octreotide analogs inhibit pancreatic exocrine secretion [42] and are used by centers as prophylactic agents to prevent POPF after pancreatic resection. Although there is still some controversy regarding the efficacy of these agents [43], two RCTs showed a decrease in POPF in patients undergoing pancreatic head resection [44, 45]. A randomized trial from Finland showed that preoperative intravenous application of hydrocortisone was not inferior to pasireotide in patients undergoing partial pancreatectomy with regard to incidence of POPF [46].

In a recent publication synthesizing perioperative risk factors for POPF, special attention was given to factors usually overlooked in pancreatic surgery which might have an effect on healing of the pancreatic anastomosis such as duration of surgery, perfusion of the pancreas, hypotension episodes, and volume of fluid transfused. Furthermore, it was suggested that metabolism, inflammasome, and the microbiome may play a role in the complex mechanisms and interactions involved in the development of POPF [47].

On univariate analysis, a negative association was seen for history of weight loss, history of pancreatitis, low postoperative CRP, and increase in PDD. On multivariate analysis, only postoperative CRP was negatively associated with POPF. A number of studies have shown that an increase in postoperative CRP correlates with postoperative complications following pancreatic surgery and POPF [48, 49]. However, the diagnostic accuracy tends to be low to moderate [50]. This can be explained by an immune-mediated response to inflammation and subsequent infection. 
Limitations of this study are its retrospective nature and missing data. However, we believe that missing data was not systematic but missing at random. Of note is the Braga et al. score, which primarily aimed to determine a score for postoperative complications. However, the major morbidity component was POPF, making the score adequate for predicting the risk of POPF. In addition, some of the older scores used the original definition of POPF, which included biochemical leak as a clinically relevant POPF, thus making the data difficult to interpolate.

We present data with a relatively high incidence of POPF, which might reduce the generalizability of the results. In order to reduce the incidence of POPF in our clinic, we created a standard operating procedure (SOP) for the management of patients planned for pancreatic head resection. This includes preoperative subcutaneous application of octreotide $100 \mu \mathrm{g}$ in high-risk patients (patients with papillary tumors, tumors of the distal biliary tract, absence of pancreatic duct dilatation), preoperative biliary tract drainage in the absence of cholangitis and bilirubin level $>150 \mu \mathrm{g} / \mathrm{l}$, and intravenous application of $100 \mathrm{mg}$ hydrocortisone during intubation. During surgery, we recommend restrictive infusion therapy. The pancreaticojejunal anastomosis is performed with synthetic, resorbable, monofilament sutures made from polymer poly-p-dioxanone (PDS). The choledochojejunostomy is also performed using PDS single button sutures, $20 \mathrm{~cm}$ distal to the pancreaticojejunal anastomosis. The gastrojejunal anastomosis with preservation of the pyloric ring is sutured in two continuous rows using PDS 5-0 suture material, $50 \mathrm{~cm}$ distal to the choledochojejunostomy. With regard to drainage placement and the management of high-risk patients, we recommend using the fistula risk score proposed by Callery et al. High-risk patients also receive hydrocortisone and octreotide postoperatively. With this SOP, we hope to reduce the incidence of POPF in our clinic.

\section{Conclusion}

We performed an analysis of the application of the selected scores using the number of citations for each of these scores in the literature to date in order to better establish our conclusion and found that the most cited score was the one by Callery et al. with 210 citations in PubMed. The scores of Braga et al. and Wellner et al. followed with approximately 60 citations each. The remaining scores were cited less than 50 times. The Mungroop et al. score is quite new and was only cited 21 times. However, this score is based on the Callery et al. score and excludes intraoperative blood loss, which was statistically non-significant in our analysis.

There are many pre-, intra-, and postoperative strategies available in the management of POPF. It is therefore of major importance to synthesize these strategies and apply them in selected high-risk patients undergoing pancreatic surgery. Correct stratification of patients is possible using most of the above risk scores. The authors of this publication believe that only a pre- and intraoperative risk stratification of patients is reasonable in order to apply additional salvage strategies during and after surgery to prevent POPFassociated morbidity and mortality. Furthermore, reducing the incidence of POPF through the selective implementation of mitigating strategies in high-risk patients could reduce POPF-related costs. The application of fistula risk scores is therefore reasonable. We suggest using the risk score proposed by Callery et al. and Mungroop et al. to predict POPF because they are easy to determine. In particular, the preand intraoperative availability of significant factors will help in making decisions relating to salvage strategies.

Abbreviations ASA: American Society of Anesthesiologists; BMI: Body mass index; CRP: C-reactive protein; CT: Computed tomography; DPPHR: Duodenum-preserving pancreatic head resection; MDP: Main pancreatic duct; PC: Pancreatic consistency; PDD: Pancreatic duct diameter; PPPD: Pancreaticoduodenectomy; PG: Pancreaticogastrostomy; PJ: Pancreaticojejunostomy; PIS: Postoperative inflammatory score; POPF: Postoperative pancreatic fistula; PPH: Postpancreatectomy hemorrhage; RCT: Randomized controlled trial; ROC: Receiver operating characteristic

Author Contribution Mariam Adamu: study conception and design, data acquisition, data analysis, data interpretation, and drafting of the manuscript. Verena Plodeck: data acquisition, data interpretation, and critical revision. Claudia Adam: data acquisition, data interpretation, and critical revision. Anne Roehnert: data acquisition, data interpretation, and critical revision. Thilo Welsch: data interpretation and critical revision. Juergen Weitz: data interpretation and critical revision. Marius Distler: study design, data interpretation, and critical revision.

Funding Open Access funding enabled and organized by Projekt DEAL. This work was funded by the Department of Visceral, Thoracic and Vascular Surgery, University Hospital Carl Gustav Carus, Technical University Dresden.

Data availability The datasets generated and analyzed during the current study are available from the corresponding author on reasonable request.

Code availability The analysis code is available from the corresponding author on reasonable request.

\section{Declarations}

Ethics approval This study was approved by the ethics committee of the Technical University of Dresden (BO-EK-62022020) and performed according to the Declaration of Helsinki of 1964 and its later amendments or comparable ethical standards.

Consent to participate Consent to participate was not applicable due to the retrospective nature of the study. 
Consent for publication Consent for publication was not applicable due to the retrospective nature of the study.

Competing interests The authors declare no competing interests.

Open Access This article is licensed under a Creative Commons Attribution 4.0 International License, which permits use, sharing, adaptation, distribution and reproduction in any medium or format, as long as you give appropriate credit to the original author(s) and the source, provide a link to the Creative Commons licence, and indicate if changes were made. The images or other third party material in this article are included in the article's Creative Commons licence, unless indicated otherwise in a credit line to the material. If material is not included in the article's Creative Commons licence and your intended use is not permitted by statutory regulation or exceeds the permitted use, you will need to obtain permission directly from the copyright holder. To view a copy of this licence, visit http://creativecommons.org/licenses/by/4.0/.

\section{References}

1. Pedrazzoli S (2017) Pancreatoduodenectomy (PD) and postoperative pancreatic fistula (POPF): A systematic review and analysis of the POPF-related mortality rate in 60,739 patients retrieved from the English literature published between 1990 and 2015. Medicine (Baltimore) 96(19):e6858. https://doi.org/10.1097/MD. 0000000000006858

2. Nentwich MF, El Gammal AT, Lemcke T, Ghadban T, Bellon E, Melling N, Bachmann K, Reeh M, Uzunoglu FG, Izbicki JR, Bockhorn M (2015) Salvage completion pancreatectomies as damage control for post-pancreatic surgery complications: a singlecenter retrospective analysis. World J Surg 39(6):1550-1556. https://doi.org/10.1007/s00268-015-2969-9

3. Welsch T, Eisele H, Zschabitz S, Hinz U, Buchler MW, Wente MN (2011) Critical appraisal of the International Study Group of Pancreatic Surgery (ISGPS) consensus definition of postoperative hemorrhage after pancreatoduodenectomy. Langenbecks Arch Surg 396(6):783-791. https://doi.org/10.1007/ s00423-011-0811-x

4. Grutzmann R, Ruckert F, Hippe-Davies N, Distler M, Saeger HD (2012) Evaluation of the International Study Group of Pancreatic Surgery definition of post-pancreatectomy hemorrhage in a highvolume center. Surgery 151(4):612-620. https://doi.org/10.1016/j. surg.2011.09.039

5. Wolk S, Grutzmann R, Rahbari NN, Hoffmann RT, Plodeck V, Weitz J, Welsch T, Distler M (2017) Management of clinically relevant postpancreatectomy hemorrhage (PPH) over two decades - a comparative study of 1450 consecutive patients undergoing pancreatic resection. Pancreatology 17(6):943-950. https://doi. org/10.1016/j.pan.2017.10.006

6. Murphy JE, Wo JY, Ryan DP, Jiang W, Yeap BY, Drapek LC, Blaszkowsky LS, Kwak EL, Allen JN, Clark JW, Faris JE, Zhu AX, Goyal L, Lillemoe KD, DeLaney TF, Fernandez-Del Castillo C, Ferrone CR, Hong TS (2018) Total neoadjuvant therapy with FOLFIRINOX followed by individualized chemoradiotherapy for borderline resectable pancreatic adenocarcinoma: a phase 2 clinical trial. JAMA Oncol 4(7):963-969. https://doi.org/10.1001/ jamaoncol.2018.0329

7. Hartwig W, Buchler MW (2013) Pancreatic cancer: current options for diagnosis, staging and therapeutic management. Gastrointest Tumors 1(1):41-52. https://doi.org/10.1159/000354992
8. Harnoss JC, Ulrich AB, Harnoss JM, Diener MK, Buchler MW, Welsch T (2014) Use and results of consensus definitions in pancreatic surgery: a systematic review. Surgery 155(1):47-57. https://doi.org/10.1016/j.surg.2013.05.035

9. Hempel S, Wolk S, Kahlert C, Kersting S, Weitz J, Welsch T, Distler M (2017) Outpatient drain management of patients with clinically relevant Postoperative Pancreatic Fistula (POPF). Langenbecks Arch Surg 402(5):821-829. https://doi.org/10.1007/ s00423-017-1595-4

10. Andrianello S, Marchegiani G, Malleo G, Masini G, Balduzzi A, Paiella S, Esposito A, Landoni L, Casetti L, Tuveri M, Salvia R, Bassi C (2020) Pancreaticojejunostomy with externalized stent vs pancreaticogastrostomy with externalized stent for patients with high-risk pancreatic anastomosis: a single-center, phase 3, randomized clinical trial. JAMA Surg. https://doi.org/10.1001/jamasurg.2019.6035

11. Bassi C, Marchegiani G, Dervenis C, Sarr M, Abu Hilal M, Adham M, Allen P, Andersson R, Asbun HJ, Besselink MG, Conlon K, Del Chiaro M, Falconi M, Fernandez-Cruz L, Fernandez-Del Castillo C, Fingerhut A, Friess H, Gouma DJ, Hackert T, Izbicki J, Lillemoe KD, Neoptolemos JP, Olah A, Schulick R, Shrikhande SV, Takada T, Takaori K, Traverso W, Vollmer CR, Wolfgang CL, Yeo CJ, Salvia R, Buchler M, International Study Group on Pancreatic S (2017) The 2016 update of the International Study Group (ISGPS) definition and grading of postoperative pancreatic fistula: 11 Years After. Surgery 161(3):584-591. https://doi.org/10.1016/j.surg.2016.11.014

12. Ansorge C, Strommer L, Andren-Sandberg A, Lundell L, Herrington MK, Segersvard R (2012) Structured intraoperative assessment of pancreatic gland characteristics in predicting complications after pancreaticoduodenectomy. Brit J Surg 99(8):1076-1082. https://doi.org/10.1002/bjs.8784

13. Braga M, Capretti G, Pecorelli N, Balzano G, Doglioni C, Ariotti R, Di Carlo V (2011) A prognostic score to predict major complications after pancreaticoduodenectomy. Ann Surg 254(5):702-708. https://doi.org/10.1097/SLA.0b013e3182 $3598 \mathrm{fb}$

14. Callery MP, Pratt WB, Kent TS, Chaikof EL, Vollmer CM (2013) A prospectively validated clinical risk score accurately predicts pancreatic fistula after pancreatoduodenectomy. J Am Coll Surgeons 216(1):1-14. https://doi.org/10.1016/j.jamcollsurg.2012.09. 002

15. Fujiwara Y, Misawa T, Shiba H, Shirai Y, Iwase R, Haruki K, Furukawa K, Futagawa Y, Yanaga K (2013) A novel postoperative inflammatory score predicts postoperative pancreatic fistula after pancreatic resection. Anticancer Res 33(11):5005-5010

16. Graham JA, Kayser R, Smirniotopoulos J, Nusbaum JD, Johnson LB (2013) Probability prediction of a postoperative pancreatic fistula after a pancreaticoduodenectomy allows for more transparency with patients and can facilitate management of expectations. J Surg Oncol 108(2):137-138. https://doi.org/10.1002/jso.23362

17. Kantor O, Talamonti MS, Pitt HA, Vollmer CM, Riall TS, Hall BL, Wang CH, Baker MS (2017) Using the NSQIP pancreatic demonstration project to derive a modified fistula risk score for preoperative risk stratification in patients undergoing pancreaticoduodenectomy. J Am Coll Surgeons 224(5):816-825. https:// doi.org/10.1016/j.jamcollsurg.2017.01.054

18. Mungroop TH, van Rijssen LB, van Klaveren D, Smits FJ, van Woerden V, Linnemann RJ, de Pastena M, Klompmaker S, Marchegiani G, Ecker BL, van Dieren S, Bonsing B, Busch OR, van Dam RM, Erdmann J, van Eijck CH, Gerhards MF, van Goor H, van der Harst E, de Hingh IH, de Jong KP, Kazemier G, Luyer M, Shamali A, Barbaro S, Armstrong T, Takhar A, Hamady Z, Klaase J, Lips DJ, Molenaar IQ, Nieuwenhuijs VB, Rupert C, van Santvoort HC, Scheepers JJ, van der Schelling GP, Bassi C, Vollmer CM, Steyerberg EW, Abu Hilal M, Groot Koerkamp B, 
Besselink MG, Dutch Pancreatic Cancer G (2019) Alternative fistula risk score for pancreatoduodenectomy (a-FRS): design and international external validation. Ann Surg 269(5):937-943. https://doi.org/10.1097/SLA.0000000000002620

19. Roberts KJ, Hodson J, Mehrzad H, Marudanayagam R, Sutcliffe RP, Muiesan P, Isaac J, Bramhall SR, Mirza DF (2014) A preoperative predictive score of pancreatic fistula following pancreatoduodenectomy. HPB 16(7):620-628. https://doi.org/10.1111/ hpb. 12186

20. Wellner UF, Kayser G, Lapshyn H, Sick O, Makowiec F, Hoppner J, Hopt UT, Keck T (2010) A simple scoring system based on clinical factors related to pancreatic texture predicts postoperative pancreatic fistula preoperatively. HPB 12(10):696-702. https:// doi.org/10.1111/j.1477-2574.2010.00239.x

21. Yamamoto Y, Sakamoto Y, Nara S, Esaki M, Shimada K, Kosuge T (2011) A preoperative predictive scoring system for postoperative pancreatic fistula after pancreaticoduodenectomy. World J Surg 35(12):2747-2755. https://doi.org/10.1007/ s00268-011-1253-x

22. R Core Team (2013) R: A language and environment for statistical computing. R Foundation for Statistical Computing, Vienna, Austria.

23. Shahbazov R, Naziruddin B, Salam O, Saracino G, Levy MF, Beecherl E, Onaca N (2020) The impact of surgical complications on the outcome of total pancreatectomy with islet autotransplantation. Am J Surg 219(1):99-105. https://doi.org/10.1016/j.amjsurg. 2019.04.007

24. Kawaida H, Kono H, Hosomura N, Amemiya H, Itakura J, Fujii H, Ichikawa D (2019) Surgical techniques and postoperative management to prevent postoperative pancreatic fistula after pancreatic surgery. World J Gastroenterol 25(28):3722-3737. https://doi.org/ 10.3748/wjg.v25.i28.3722

25. Grendar J, Ouellet JF, Sutherland FR, Bathe OF, Ball CG, Dixon E (2015) In search of the best reconstructive technique after pancreaticoduodenectomy: pancreaticojejunostomy versus pancreaticogastrostomy. Can J Surg 58(3):154-159. https://doi.org/10. 1503/cjs. 010014

26. Ricci C, Casadei R, Taffurelli G, Pacilio CA, Beltrami D, Minni $F(2017)$ Is pancreaticogastrostomy safer than pancreaticojejunostomy after pancreaticoduodenectomy? A meta-regression analysis of randomized clinical trials. Pancreatology 17(5):805-813. https://doi.org/10.1016/j.pan.2017.07.003

27. Crippa S, Cirocchi R, Randolph J, Partelli S, Belfiori G, Piccioli A, Parisi A, Falconi M (2016) Pancreaticojejunostomy is comparable to pancreaticogastrostomy after pancreaticoduodenectomy: an updated meta-analysis of randomized controlled trials. Langenbecks Arch Surg 401(4):427-437. https://doi.org/10.1007/ s00423-016-1418-z

28. Hallet J, Zih FS, Deobald RG, Scheer AS, Law CH, Coburn NG, Karanicolas PJ (2015) The impact of pancreaticojejunostomy versus pancreaticogastrostomy reconstruction on pancreatic fistula after pancreaticoduodenectomy: meta-analysis of randomized controlled trials. HPB (Oxford) 17(2):113-122. https://doi.org/ 10.1111/hpb.12299

29. Perivoliotis K, Sioka E, Tatsioni A, Stefanidis I, Zintzaras E, Zacharoulis D (2017) Pancreatogastrostomy versus pancreatojejunostomy: an up-to-date meta-analysis of RCTs. Int J Surg Oncol 2017:7526494. https://doi.org/10.1155/2017/7526494

30. El Nakeeb A, Hamdy E, Sultan AM, Salah T, Askr W, Ezzat H, Said M, Zeied MA, Abdallah T (2014) Isolated Roux loop pancreaticojejunostomy versus pancreaticogastrostomy after pancreaticoduodenectomy: a prospective randomized study. HPB (Oxford) 16(8):713-722. https://doi.org/10.1111/hpb.12210

31. Tomimaru Y, Takeda Y, Kobayashi S, Marubashi S, Lee CM, Tanemura M, Nagano H, Kitagawa T, Dono K, Umeshita K, Wakasa K, Monden M (2009) Comparison of postoperative morphological changes in remnant pancreas between pancreaticojejunostomy and pancreaticogastrostomy after pancreaticoduodenectomy. Pancreas 38(2):203-207. https://doi.org/10.1097/ MPA.0b013e31818e1772

32. Witzigmann H, Diener MK, Kienkotter S, Rossion I, Bruckner T, Barbel W, Pridohl O, Radulova-Mauersberger O, Lauer H, Knebel P, Ulrich A, Strobel O, Hackert T, Buchler MW (2016) No need for routine drainage after pancreatic head resection: the dual-center, randomized, controlled PANDRA trial (ISRCTN04937707). Ann Surg 264(3):528-537. https://doi. org/10.1097/SLA.0000000000001859

33. Van Buren G, 2nd, Bloomston M, Hughes SJ, Winter J, Behrman SW, Zyromski NJ, Vollmer C, Velanovich V, Riall T, Muscarella P, Trevino J, Nakeeb A, Schmidt CM, Behrns K, Ellison EC, Barakat O, Perry KA, Drebin J, House M, Abdel-Misih S, Silberfein EJ, Goldin S, Brown K, Mohammed S, Hodges SE, McElhany A, Issazadeh M, Jo E, Mo Q, Fisher WE (2014) A randomized prospective multicenter trial of pancreaticoduodenectomy with and without routine intraperitoneal drainage. Ann Surg 259 (4):605-612. https://doi.org/10.1097/SLA.00000 00000000460

34. Motoi F, Egawa S, Rikiyama T, Katayose Y, Unno M (2012) Randomized clinical trial of external stent drainage of the pancreatic duct to reduce postoperative pancreatic fistula after pancreaticojejunostomy. Br J Surg 99(4):524-531. https://doi.org/10.1002/ bjs. 8654

35. Pessaux P, Sauvanet A, Mariette C, Paye F, Muscari F, Cunha AS, Sastre B, Arnaud JP, de Recherche F, en C, (2011) External pancreatic duct stent decreases pancreatic fistula rate after pancreaticoduodenectomy: prospective multicenter randomized trial. Ann Surg 253(5):879-885. https://doi.org/10.1097/SLA.0b013e3182 1219af

36. Ochiai T, Sonoyama T, Soga K, Inoue K, Ikoma H, Shiozaki A, Kuriu Y, Kubota T, Nakanishi M, Kikuchi S, Ichikawa D, Fujiwara H, Sakakura C, Okamoto K, Kokuba Y, Otsuji E (2010) Application of polyethylene glycolic acid felt with fibrin sealant to prevent postoperative pancreatic fistula in pancreatic surgery. J Gastrointest Surg 14(5):884-890. https://doi.org/10.1007/ s11605-009-1149-3

37. Gong J, He S, Cheng Y, Cheng N, Gong J, Zeng Z (2018) Fibrin sealants for the prevention of postoperative pancreatic fistula following pancreatic surgery. Cochrane Database Syst Rev 6:CD009621. https://doi.org/10.1002/14651858.CD009621. pub3

38. Martin I, Au K (2013) Does fibrin glue sealant decrease the rate of anastomotic leak after a pancreaticoduodenectomy? Results of a prospective randomized trial. HPB (Oxford) 15(8):561-566. https://doi.org/10.1111/hpb.12018

39. Lillemoe KD, Cameron JL, Kim MP, Campbell KA, Sauter PK, Coleman JA, Yeo CJ (2004) Does fibrin glue sealant decrease the rate of pancreatic fistula after pancreaticoduodenectomy? Results of a prospective randomized trial. J Gastrointest Surg 8 (7):766772; discussion 772-764. https://doi.org/10.1016/j.gassur.2004. 06.011

40. Ramia JM, de la Plaza R, Adel F, Ramiro C, Arteaga V, GarciaParreno J (2014) Wrapping in pancreatic surgery: a systematic review. ANZ J Surg 84(12):921-924. https://doi.org/10.1111/ans. 12491

41. Mussle B, Wierick A, Distler M, Weitz J, Welsch T (2017) Falciform ligament wrap for prevention of gastroduodenal artery bleed after pancreatoduodenectomy. J Surg Res 207:215-222. https:// doi.org/10.1016/j.jss.2016.08.087

42. Harris AG (1994) Somatostatin and somatostatin analogues: pharmacokinetics and pharmacodynamic effects. Gut 35(3 Suppl):S1-4. https://doi.org/10.1136/gut.35.3_suppl.s1 
43. Koti RS, Gurusamy KS, Fusai G, Davidson BR (2010) Metaanalysis of randomized controlled trials on the effectiveness of somatostatin analogues for pancreatic surgery: a Cochrane review. HPB (Oxford) 12(3):155-165. https://doi.org/10.1111/j.14772574.2010.00157.x

44. Shan YS, Sy ED, Lin PW (2003) Role of somatostatin in the prevention of pancreatic stump-related morbidity following elective pancreaticoduodenectomy in high-risk patients and elimination of surgeon-related factors: prospective, randomized, controlled trial. World J Surg 27(6):709-714. https://doi.org/10.1007/ s00268-003-6693-5

45. Gouillat C, Chipponi J, Baulieux J, Partensky C, Saric J, Gayet B (2001) Randomized controlled multicentre trial of somatostatin infusion after pancreaticoduodenectomy. Br J Surg 88(11):14561462. https://doi.org/10.1046/j.0007-1323.2001.01906.x

46. Tarvainen T, Siren J, Kokkola A, Sallinen V (2020) Effect of hydrocortisone vs pasireotide on pancreatic surgery complications in patients with high risk of pancreatic fistula: a randomized clinical trial. JAMA Surg. https://doi.org/10.1001/jamasurg.2019.6019

47. Soreide K, Healey AJ, Mole DJ, Parks RW (2019) Pre-, peri- and post-operative factors for the development of pancreatic fistula after pancreatic surgery. HPB (Oxford) 21(12):1621-1631. https:// doi.org/10.1016/j.hpb.2019.06.004
48. Partelli S, Pecorelli N, Muffatti F, Belfiori G, Crippa S, Piazzai F, Castoldi R, Marmorale C, Balzano G, Falconi M (2017) Early postoperative prediction of clinically relevant pancreatic fistula after pancreaticoduodenectomy: usefulness of C-reactive protein. HPB (Oxford) 19(7):580-586. https://doi.org/10.1016/j.hpb.2017. 03.001

49. Welsch T, Frommhold K, Hinz U, Weigand MA, Kleeff J, Friess H, Buchler MW, Schmidt J (2008) Persisting elevation of C-reactive protein after pancreatic resections can indicate developing inflammatory complications. Surgery 143(1):20-28. https://doi. org/10.1016/j.surg.2007.06.010

50. Warschkow R, Ukegjini K, Tarantino I, Steffen T, Muller SA, Schmied BM, Marti L (2012) Diagnostic study and metaanalysis of C-reactive protein as a predictor of postoperative inflammatory complications after pancreatic surgery. J Hepatobiliary Pancreat Sci 19(4):492-500. https://doi.org/10.1007/ s00534-011-0462-x

Publisher's note Springer Nature remains neutral with regard to jurisdictional claims in published maps and institutional affiliations. 